\title{
La economía y las finanzas en Evangelii gaudium: una reflexión sobre algunas reacciones en Estados Unidos desde la Doctrina Social de la Iglesia
}

\author{
Gregorio Guitián \\ FACULTAD DE TEOLOGÍA \\ UNIVERSIDAD DE NAVARRA \\ gguitian@unav.es
}

Resumen: La Exhortación Apostólica Evangelii gaudium (EvG) ha sido recibida positivamente por la opinión pública. Sin embargo los pasajes de sobre la economía han suscitado algunas reacciones críticas en Estados Unidos. La tendencia a leer en clave política el magisterio sobre cuestiones sociales, un problema particular en la traducción del texto y el estilo y finalidad del documento son algunos factores que han influido de diverso modo en la comprensión de esos pasajes. En este trabajo se expone, en el marco de la Doctrina Social de la Iglesia anterior, los aspectos principales del mensaje de EvG sobre el sistema económico actual y, desde ahí, se presentan y analizan algunas reacciones al documento en Estados Unidos. Por último, el autor extrae cinco conclusiones.

Palabras clave: Evangelii gaudium, Doctrina Social de la Iglesia, Capitalismo, Justicia social, inclusión social de los pobres, Estados Unidos de América.

Abstract: The Apostolic Exhortation Evangelii gaudium (EvG) has been positively received by public opinion. However, the paragraphs on Economy have raised some critizism in the United States. A tendency to make a political reading of the magisterium on social issues, a particular problem with the translation, and the stile and aim of the document are some of the factors which have influenced in various ways the understanding of those paragraphs. This article presents the main points of the message of EvG on the current economic system in light of previous Catholic Social Teaching. Then some reactions to this document in the United States are presented and analyzed. Finally, the author draws five conclusions.

Keywords: Evangelii gaudium, Catholic Social Teaching, Capitalism, Social justice, inclusion of the poor in society, United States of America. 


\section{INTRODUCCIÓN}

El 24 de noviembre de 2013, el día de la clausura del Año de la fe, el papa Francisco firmaba la Exhortación Apostólica Evangelii gaudium (EvG), sobre el anuncio del Evangelio en el mundo actual. No era el primer gran documento magisterial de Francisco, puesto que pocos meses antes había publicado la encíclica Lumen fidei, pero captó la atención de los medios de comunicación y generó un debate en el ámbito académico y en la opinión pública como no se había visto desde hacía tiempo. Las reacciones han sido de diverso grado en función de los países. Por ejemplo, en la opinión pública española, poco acostumbrada a una reflexión de calado sobre las intervenciones del magisterio pontificio, el eco ha sido escaso y, salvo excepciones, más bien superficial; mientras que en el ámbito académico ha destacado el vivo debate entre profesores de diversas universidades españolas en el seno de la Asociación para el Estudio de la Doctrina Social de la Iglesia (AEDOS), sobre todo a través del intercambio de notas y de dos seminarios especiales dedicados a ese documento. Sin embargo y en el conjunto, nos ha llamado la atención el impacto que han causado en Estados Unidos los pasajes de la Exhortación sobre la economía y las finanzas, hasta el punto de que el mismo Presidente de la nación citó expresamente un pasaje del documento en un discurso importante sobre la desigualdad, y el propio Francisco respondió indirectamente en una entrevista a ciertos comentarios realizados en Estados Unidos.

Este es el contexto de este trabajo, que tiene por objetivo presentar una reflexión sobre el contenido económico de EvG desde la perspectiva de la Doctrina Social de la Iglesia y en diálogo con algunas reacciones provocadas por el documento en Estados Unidos. En primer lugar nos detendremos en las características del documento, que son particulares, después nos fijaremos en lo que la DSI ha afirmado sobre las cuestiones económicas mencionadas por el papa Francisco en la Exhortación. A continuación expondremos el núcleo central de los números del documento que se refieren a cuestiones económicas para luego señalar y comentar algunas reacciones significativas en Estados Unidos. Por último presentamos cinco conclusiones extraídas del análisis realizado.

\section{EL DOCUMENTO Y SU CONTEXTO}

Como es sabido EvG es la exhortación apostólica que sigue al Sínodo sobre la nueva evangelización celebrado en Roma en octubre de 2012. 
Benedicto XVI había creado en septiembre de 2010 el Pontificio Consejo para la Promoción de la Nueva Evangelización porque consideraba que ese es un reto importante para la Iglesia actual: la situación de los países de honda tradición cristiana que, sin embargo, han ido perdiendo paulatinamente su identidad cristiana debido a un agudo proceso de secularización. En ese contexto Benedicto XVI convocó un sínodo para reflexionar sobre la nueva evangelización y, todavía siendo él Romano Pontífice, presidió el sínodo y recibió de este 58 proposiciones finales como resultado de la reflexión de los participantes en el sínodo ${ }^{1}$. Ese material llegó al papa Francisco, que aceptó la petición de los padres sinodales de redactar una Exhortación Apostólica, "sobre el anuncio del Evangelio en el mundo actual".

EvG es un largo documento dirigido fundamentalmente a espolear el afán evangelizador de toda la Iglesia, no solo de la jerarquía ${ }^{2}$. Se diría que Francisco quiere hacer ver a todos los católicos -y a los cristianosel tesoro que tienen entre manos, y cómo ese tesoro no puede quedar encerrado en los muros de los edificios de culto: ha de llegar al mundo porque la alegría del Evangelio es para todo el mundo. Por eso desde el primer momento predomina el tono animante y positivo, de manera particular en el impresionante comienzo (EvG 1-13) donde Francisco presenta, a modo de pórtico de lo que quiere transmitir, la potencia, la fuerza que tiene el Evangelio para iluminar y alegrar la vida de la humanidad. Describe así, repasando el Antiguo y Nuevo Testamento, cómo la alegría ha sido siempre el signo de la presencia de Dios en el mundo, y cómo Jesucristo ha traído, con su presencia y el anuncio de su Evangelio, la fuente de la alegría al mundo.

El esquema de la Exhortación, dividida en cinco capítulos, da cuenta de la amplitud temática y pone de relieve en primer lugar que EvG no es un documento magisterial destinado a formar parte del magisterio social o DSI: a) la reforma de la Iglesia en salida misionera (la Iglesia debe "salir" al mundo); b) las tentaciones de los agentes pastorales y un repaso de la situación extraeclesial; c) la Iglesia entendida como la totalidad

1 La Santa Sede publicó la versión inglesa de las proposiciones: cfr. http://www.vatican. va/news_services/press/sinodo/documents/bollettino_25_xiii-ordinaria-2012/02_ inglese/b33_02.html - FINAL_LIST_OF_PROPOSITIONS (accedido en marzo de 2014).

2 El documento tiene cerca de 53.000 palabras distribuidas en 288 números. 
del Pueblo de Dios que evangeliza, donde el Papa pone énfasis en que no puede haber auténtica evangelización sin la proclamación explícita de que Jesús es el Señor; d) la homilía y su preparación; e) la inclusión social de los pobres y la dimensión social de la evangelización; f) la paz y el diálogo social; el bien común y la paz social, y g) las motivaciones espirituales para la tarea misionera. Como se ve, aunque indudablemente toca temas de la DSI, como en la sección sobre la dimensión social de la evangelización ${ }^{3}$, el conjunto del documento se mueve más en el terreno pastoral.

La segunda característica, que a nuestro entender influye notablemente en algunas reacciones al documento, es el estilo o registro lingüístico que emplea el papa Francisco. A lo largo del documento se pueden encontrar frases vigorosas, redondas, expresivas, que buscan llegar de manera directa al interlocutor, incluso creando cuando es necesario nuevos términos ${ }^{4}$. Junto a las expresiones que se refieren a los números que tratan sobre la economía y las finanzas, tales como "no a una economía de la exclusión" (EvG 53), "no a la nueva idolatría del dinero" (55), "no a un dinero que gobierna en lugar de servir" (57), "no a la inequidad que genera violencia" (59), "ya no podemos confiar en las fuerzas ciegas y en la mano invisible del mercado" (204), etc., encontramos también

3 De entre las 58 proposiciones de los padres, una, la 24a , hace referencia a la DSI: "Con el fin de promover una nueva evangelización en la sociedad, la mayor atención se debe dar a la doctrina social de la Iglesia, entendiendo que se trata de un anuncio y el testimonio de la fe, un medio insustituible de la educación en la fe (cf. Caritas in veritate, 15). Este abrazo de la doctrina social de la Iglesia debe estar presente en el contenido de la catequesis, la educación cristiana, la formación de los seminaristas y religiosos, la formación permanente de los obispos y de los sacerdotes y sobre todo la formación de los laicos. El Compendio de la Doctrina Social de la Iglesia es un recurso muy valioso en el logro de esta formación continua”. Además, la proposición 31 se refería a la nueva evangelización y la opción por los pobres, subrayando que los más afectados por la crisis económica son los sin-techo, los abandonados y los inmigrantes. "La opción preferencial por los pobres nos lleva a buscar a los pobres y trabajar en su nombre para que se sienta como en casa en la Iglesia. Ambos son destinatarios y actores de la Nueva Evangelización”. Esta es la única referencia a la economía, y como se ha visto, Francisco se ha ocupado expresamente de este tema en la Exhortación Apostólica.

4 Por ejemplo "primerear", que se refiere a adelantarse, tener iniciativa: "la Iglesia en salida es la comunidad de discípulos misioneros que primerean, que se involucran, que acompañan, que fructifican y festejan. «Primerear»: sepan disculpar este neologismo" (EvG 24). 
abundantes ejemplos en otros contextos ${ }^{5}$. Muchas de esas expresiones son palmarias y no necesitan explicación alguna; otras, en cambio, si se toman aisladamente, pueden dar lugar a algún equívoco.

EL MARCO DE LA DOCTRINA SOCIAL DE LA IGLESIA QUE SITÚA LOS NÚMEROS DE EVG SOBRE LA ECONOMÍA

Pocas semanas después de la publicación de EvG, el Papa afirmaba en una entrevista que "en la Exhortación no hay nada que no se encuentre en la Doctrina social de la Iglesia"6. Por eso, y a la vista de algunas reacciones al documento, es importante exponer de manera breve y sintética lo que la DSI ha dicho a propósito del libre mercado.

En distintos documentos, pero de manera especial en la encíclica Centesimus annus, la DSI ha elogiado abiertamente lo que llama "economía de mercado o simplemente economía libre"7, así como el libre mercado por ser, en la práctica, "el instrumento más eficaz para colocar

5 "Los evangelizadores tienen así «olor a oveja»" (24); "constituyámonos en todas las regiones de la tierra en un "estado permanente de misión»" (25); "sin "fidelidad de la Iglesia a la propia vocación», cualquier estructura nueva se corrompe en poco tiempo" (26); "sueño con una opción misionera capaz de transformarlo todo" (27); "prefiero una Iglesia accidentada, herida y manchada por salir a la calle, antes que una Iglesia enferma por el encierro y la comodidad de aferrarse a las propias seguridades" (49); "estamos llamados a ser personas-cántaros para dar de beber a los demás" (86); "la inequidad es la raíz de los males sociales" (202); "nos entretenemos vanidosos hablando sobre "lo que habría que hacer" -el pecado del "habriaqueísmo»"- (96); "tampoco creo que deba esperarse del magisterio papal una palabra definitiva o completa sobre todas las cuestiones que afectan a la Iglesia y al mundo" (16); "no es conveniente que el Papa reemplace a los episcopados locales en el discernimiento de todas las problemáticas que se plantean en sus territorios. En este sentido, percibo la necesidad de avanzar en una saludable "descentralización»" (16); "una pastoral en clave misionera no se obsesiona por la transmisión desarticulada de una multitud de doctrinas que se intenta imponer a fuerza de insistencia" (35); "si un párroco a lo largo de un año litúrgico habla diez veces sobre la templanza y solo dos o tres veces sobre la caridad o la justicia, se produce una desproporción donde las que se ensombrecen son precisamente aquellas virtudes que deberían estar más presentes en la predicación y en la catequesis" (38), etc.

6 Cfr. Francisco, "Jamás tener miedo a la ternura", en La Stampa 14-12-2013. (http://www.lastampa.it/2013/12/14/esteri/vatican-insider/es/jams-tener-miedoa-la-ternura-r8lpFUAxsH2v9Ypu21 FPeI/pagina.html. Accedido marzo 2014).

7 Juan Pablo II, Enc. Centesimus annus, 42 (AAS 83 [1991] 793-867). En adelante CA. 
los recursos y responder eficazmente a las necesidades"8. De ahí que el Compendio reconozca que "históricamente, el mercado ha dado prueba de saber iniciar y sostener, a largo plazo, el desarrollo económico" ${ }^{\text {. En }}$ conjunto

"la doctrina social de la Iglesia aprecia las seguras ventajas que ofrecen los mecanismos del libre mercado, tanto para utilizar mejor los recursos, como para agilizar el intercambio de productos: estos mecanismos, sobre todo, dan la primacía a la voluntad y a las preferencias de la persona, que, en el contrato, se confrontan con las de otras personas" (CDSI 347).

Además, y este es un punto importante, la DSI es consciente de que "un mercado verdaderamente competitivo es un instrumento eficaz para conseguir importantes objetivos de justicia: moderar los excesos de ganancia de las empresas; responder a las exigencias de los consumidores; realizar una mejor utilización y ahorro de los recursos; premiar los esfuerzos empresariales y la habilidad de innovación; hacer circular la información, de modo que realmente se puedan comparar y adquirir los productos en un contexto de sana competencia" (CDSI 347).

De modo particular, se reconoce bajo estas condiciones la capacidad del mercado de responder a las exigencias de la justicia conmutativa ${ }^{10}$.

Sin embargo la DSI ha sido igualmente clara respecto a las limitaciones del mercado, que no es un instrumento perfecto al que se le pueda pedir solución para todos los problemas económicos. Juan Pablo II apuntó agudamente que el mercado da una respuesta adecuada

"solo para aquellas necesidades que son «solventables", con poder adquisitivo, y para aquellos recursos que son «vendibles», esto es, capaces de alcanzar un precio conveniente. Pero existen numerosas necesidades humanas que no tienen salida en el mercado. Es un estricto deber de justicia y de verdad impedir que queden sin satisfacer las necesidades humanas fundamentales y que perezcan los hombres oprimidos por ellas" (CA 34).

CA 34.

9 Pontificio Consejo Justicia y Paz, Compendio de la Doctrina Social de la Iglesia (BAC-Planeta, Madrid 2005) 347. En adelante CDSI.

10 Cfr. Benedicto XVI, Enc. Caritas in veritate, 35 (AAS 101 [2009] 641-709). En adelante $\mathrm{CV}$. 
Se trata de un punto delicado. Por una parte, hay importantes necesidades humanas que no se le pueden pedir al mercado: uno puede comprar una casa pero no puede comprar un hogar, ni tampoco se puede comprar el amor que toda persona necesita. Del mismo modo, tampoco el mercado es capaz de dar respuesta a todas las necesidades de índole espiritual, por mencionar algunos ejemplos.

Por otra parte, aquellas personas que sin culpa propia no tienen la capacidad adquisitiva para participar en el mercado, por ejemplo porque a causa de un accidente han perdido su trabajo o ya no tienen posibilidad de encontrar uno nuevo, quedan excluidas de ese ámbito y pueden llegar a carecer incluso de lo necesario para vivir. No se trata simplemente de una situación triste sino también de una injusticia. En concreto, la justicia social, es decir, la justicia del bien común, la que se refiere al deber de contribuir al bien común según sus posibilidades, exige que esas personas no queden excluidas de la sociedad. Cuando a una persona sin culpa propia le falta lo necesario para sobrevivir, queda excluida no solo del mercado sino también de la sociedad, y se le niega la dignidad de poder participar del bien común que supone vivir en sociedad, la dignidad de poder contribuir a ese bien común. Por justicia social una sociedad debe poner los medios para que esas personas no queden excluidas. Un primer paso es que puedan tener lo más básico para no perecer, pero el verdadero objetivo es cómo ayudarlas para que sean capaces de contribuir al bien común cumpliendo con sus deberes, cómo crear oportunidades para esas personas. Como tal y por sí mismo, el mercado no sabe hacer eso porque no es capaz de responder a las exigencias de la justicia social y por eso necesita algo más ${ }^{11}$. Esa corrección, ese complemento, es orientación al bien común, y eso es lo que hace notar la DSI, que

11 Un ejemplo significativo es el origen de los microcréditos. Como es sabido Yunus se dio cuenta de que no pocas mujeres que trabajaban fatigosamente en la elaboración y venta de manufacturas sencillas difícilmente podían sostener a sus familias por tener que hacer frente a los considerables gastos de la exigua financiación que obtenían de particulares para poder llevar a cabo ese trabajo. El margen que les quedaba para vivir era muy reducido. No podían acudir a la banca comercial por carecer de aval o garantía porque, básicamente, no tenían nada. No tenían capacidad de acceder al mercado. Desde el punto de vista de la justicia social en ese punto existía un problema. Yunus introdujo la figura del microcrédito, que en esencia concedía la financiación sin garantía, fiándose del trabajo de esas personas y con un interés menor. De ese modo fueron capaces de sacar adelante sus negocios (y sus familias) más dignamente. (cfr. P. Rosamunde, El banquero de los pobres: los 
"[...] no ha dejado nunca de subrayar la importancia de la justicia distributiva y de la justicia social para la economía de mercado, no solo porque está dentro de un contexto social y político más amplio, sino también por la trama de relaciones en que se desenvuelve. En efecto, si el mercado se rige únicamente por el principio de la equivalencia del valor de los bienes que se intercambian, no llega a producir la cohesión social que necesita para su buen funcionamiento. Sin formas internas de solidaridad y de confianza recíproca, el mercado no puede cumplir plenamente su propia función económica" (CV 35).

Por este motivo también la DSI ha llamado a la intervención de quienes tienen una especial responsabilidad respecto al bien común. Sin embargo la DSI, porque subraya igualmente la importancia del principio de subsidiaridad, sabe también que la autoridad pública, el Estado, no es la primera instancia que debe solucionar esos problemas, sino cada ciudadano y las asociaciones intermedias, como sucede en el caso de la aparición de los microcréditos o en otras iniciativas que operan dentro del mismo mercado, como las empresas de Economía de Comunión a las que se refiere "Caritas in veritate" (cfr. CV 46) ${ }^{12}$.

Como síntesis, el Catecismo de la Iglesia señala que las críticas al sistema capitalista se refieren a excesos que se dan en su "práctica" como el hacer de los beneficios el fin último, el individualismo o el tratar el trabajo humano como si fuera una mera mercancía. Y por otra parte, el Catecismo critica también algunas deficiencias respecto a la justicia social que exigen un marco ético y jurídico en vistas al bien común:

“Toda práctica que reduce a las personas a no ser más que medios con vistas al lucro esclaviza al hombre, conduce a la idolatría del dinero y contribuye a difundir el ateísmo. «No podéis servir a Dios y

microcréditos y la batalla contra la pobreza en el mundo (Paidós, Barcelona 2006). Yunus introdujo una modificación en el mercado, modificación que responde a lo que hoy llamaríamos la lógica del don o de la gratuidad (formas de confianza que abren posibilidades nuevas). Por sí mismo el mercado, que se rige por la justicia conmutativa, no era capaz de dar respuesta a esa situación. Yunus, con mucho esfuerzo y tras salvar numerosos obstáculos de tipo legal o institucional, logró mejorar la situación desde el mismo mercado. Este ejemplo muestra los límites del mercado y, al mismo tiempo, la realidad de que el Estado no es necesariamente el único cauce para solucionar los problemas de justicia social.

12 Cfr. V. Pelligra, Economía de comunión. Una nueva cultura (Ciudad Nueva, Madrid 2006); L. Bruni (coord.), Economía de comunión. Por una nueva cultura económica centrada en la persona (Ciudad Nueva, Madrid 2001). 
al dinero» (Mt 6, 24; Lc 16, 13). [...] La Iglesia ha rechazado [...] en la práctica del «capitalismo» el individualismo y la primacía absoluta de la ley de mercado sobre el trabajo humano (cf CA 10. 13. 44). La regulación de la economía [...] únicamente por la ley de mercado quebranta la justicia social, porque «existen numerosas necesidades humanas que no pueden ser satisfechas por el mercado» (CA 34). Es preciso promover una regulación razonable del mercado y de las iniciativas económicas, según una justa jerarquía de valores y con vistas al bien común" (CEC 2424-5) $)^{13}$.

\section{LOS PASAJES SOBRE LA ECONOMÍA DE EVANGELII GAUDIUM}

Los pasajes que más atención han recibido han sido precisamente los quince números o párrafos que hacen referencia a la economía y las finanzas (EvG 53-60 y 202-208). Sin embargo, lo primero que hay que decir es que esos párrafos son secundarios respecto a la temática principal de la Exhortación, que es el anuncio del Evangelio. Ese anuncio tiene sin duda una dimensión social importante porque el amor de Dios se traduce necesariamente en el amor a los demás, en la preocupación por la buena marcha de la sociedad y, en particular, en el compromiso con quienes están más necesitados (cfr. EvG 186ss). En ese contexto los números dedicados a la economía señalan, en síntesis, una preocupación de fondo del Papa: el sistema económico y financiero actual no está suficientemente orientado a la persona, no está suficientemente informado por la ética y tiene una carencia antropológica seria. Esa carencia se traduce en que lo que gobierna es el dinero, con consecuencias deshumanizadoras como la exclusión, la inequidad, el consumismo, etc. (EvG 57-58, 203). Se trata, por tanto, de que quienes tienen capacidad de decisión en el ámbito político y económico inicien un proceso para cambiar desde su raíz esta situación (EvG 203 y 205).

13 Y más recientemente el Compendio afirma: "la idea que se pueda confiar solo al mercado el suministro de todas las categorías de bienes no puede compartirse, porque se basa en una visión reductiva de la persona y de la sociedad. Ante el riesgo concreto de una «idolatría» del mercado, la doctrina social de la Iglesia subraya sus límites, fácilmente perceptibles en su comprobada incapacidad de satisfacer importantes exigencias humanas, que requieren bienes que, "por su naturaleza, no son ni pueden ser simples mercancías», bienes no negociables según la regla del «intercambio de equivalentes» y la lógica del contrato, típicas del mercado" (CDSI 349). 
La primera referencia (EvG 53-60) se encuentra en la sección dedicada a los desafíos extraeclesiales y la segunda dentro de una sección titulada "la inclusión social de los pobres", más en concreto en el apartado "economía y distribución de ingreso". El marco de la inclusión social de los pobres es muy importante para entender todo lo que se dice sobre la economía porque es ese el objetivo y la razón por la que el Papa se adentra en las cuestiones económicas. De hecho los párrafos sobre economía dentro de la sección dedicada a los desafíos extraeclasiales también están centrados en el problema de la exclusión social de los pobres.

Por otra parte es igualmente importante señalar que ambos pasajes están flanqueados por dos afirmaciones que son clave para entender la intención del Pontífice y lo que se puede encontrar en los párrafos sobre la economía. La primera es que "no es función del Papa ofrecer un análisis detallado y completo sobre la realidad contemporánea, pero aliento a todas las comunidades a una "siempre vigilante capacidad de estudiar los signos de los tiempos»" (EvG 51). En esa misma línea afirma que cuando describe la situación "solo pretendo detenerme brevemente, con una mirada pastoral, en algunos aspectos de la realidad" que influyen en la misión evangelizadora de la Iglesia. La segunda afirmación está relacionada con el enfoque pastoral de lo que el Papa dice sobre la economía:
"Si alguien se siente ofendido por mis palabras, le digo que las expre- so con afecto y con la mejor de las intenciones, lejos de cualquier in- terés personal o ideología política. Mi palabra no es la de un enemigo ni la de un opositor. Solo me interesa procurar que aquellos que están esclavizados por una mentalidad individualista, indiferente y egoísta, puedan liberarse de esas cadenas indignas y alcancen un estilo de vida y de pensamiento más humano, más noble, más fecundo, que dignifique su paso por esta tierra” (EvG 208).

Como resultado de ambas afirmaciones en la Exhortación encontramos dos tipos de frases claramente diferenciados:

a) por un lado, frases de tipo analítico donde Francisco describe algunos aspectos de la situación socioeconómica actual. Estos pasajes, como él mismo afirma, no constituyen un análisis ni detallado ni completo y aparece orientado hacia las consecuencias pastorales. 
b) Por otro lado frases de tipo exhortativo, porque el Papa quiere incidir en las personas que, de un modo u otro, están involucradas en esos campos $^{14}$.

En ambos tipos de frases el Papa emplea en ocasiones el estilo propio que antes hemos mencionado. Este marco indica que no puede esperarse de esos párrafos un tratamiento sistemático y preciso de las gruesas cuestiones apuntadas en ellos. Perder de vista este condicionamiento ha llevado fácilmente a interpretaciones parciales y a leer en un número reducido de frases más de lo que podían dar de acuerdo con la propia intención del Romano Pontífice.

En el conjunto de los quince números se detectan dos grandes ideas de fondo que están presentes en las dos secciones que hablan de economía.

\section{a) El problema de la exclusión social}

La atención mediática y gran parte de los comentarios aparecidos en Estados Unidos se han concentrado en gran medida en algunas frases de los números 53 y 54. En esas frases Francisco denuncia la exclusión e inequidad que provoca en la práctica el sistema económico actual. Por ejemplo, la frase "no puede ser que no sea noticia que muere de frío un anciano en situación de calle y que sí lo sea una caída de dos puntos en la bolsa. Eso es exclusión", fue citada expresamente por el Presidente de los Estados Unidos en un importante discurso sobre desigualdad económi-

14 Cfr. EvG 57, 58 y 205. "Animo a los expertos financieros y a los gobernantes de los países a considerar las palabras de un sabio de la antigüedad: "No compartir con los pobres los propios bienes es robarles y quitarles la vida. No son nuestros los bienes que tenemos, sino suyos" (57); "el Papa ama a todos, ricos y pobres, pero tiene la obligación, en nombre de Cristo, de recordar que los ricos deben ayudar a los pobres, respetarlos, promocionarlos. Os exhorto a la solidaridad desinteresada y a una vuelta de la economía y las finanzas a una ética en favor del ser humano" (58); “ipido a Dios que crezca el número de políticos capaces de entrar en un auténtico diálogo que se oriente eficazmente a sanar las raíces profundas y no la apariencia de los males de nuestro mundo!” (205); “¡Ruego al Señor que nos regale más políticos a quienes les duela de verdad la sociedad, el pueblo, la vida de los pobres! Es imperioso que los gobernantes y los poderes financieros levanten la mirada y amplíen sus perspectivas, que procuren que haya trabajo digno, educación y cuidado de la salud para todos los ciudadanos. ¿Y por qué no acudir a Dios para que inspire sus planes? Estoy convencido de que a partir de una apertura a la trascendencia podría formarse una nueva mentalidad política y económica que ayudaría a superar la dicotomía absoluta entre la economía y el bien común social" (205). 
$\mathrm{ca}^{15}$. Pero más allá de ese ejemplo gráfico, que Francisco había utilizado ya meses antes ${ }^{16}$, la cuestión principal es que

"hoy todo entra dentro del juego de la competitividad y de la ley del más fuerte, donde el poderoso se come al más débil. Como consecuencia de esta situación, grandes masas de la población se ven excluidas y marginadas: sin trabajo, sin horizontes, sin salida. [...] con la exclusión queda afectada en su misma raíz la pertenencia a la sociedad en la que se vive" [...] (EvG 53).

Sin embargo, acompaña a esta consideración el párrafo que ha inflamado el debate en los Estados Unidos y en otros países, y que se refiere todavía al problema de la desigualdad y la exclusión:

"En este contexto, algunos todavía defienden las teorías del "derrame", que suponen que todo crecimiento económico, favorecido por la libertad de mercado, logra provocar por sí mismo mayor equidad e inclusión social en el mundo. Esta opinión, que jamás ha sido confirmada por los hechos, expresa una confianza burda e ingenua en la bondad de quienes detentan el poder económico y en los mecanismos sacralizados del sistema económico imperante. Mientras tanto, los excluidos siguen esperando" (EG 54).

En cuanto al problema de la exclusión, a la luz de cuanto ha venido enseñando la DSI, las afirmaciones del papa Francisco no son ninguna novedad. El Pontífice está señalando que el mercado no está siendo capaz de dar respuesta a las necesidades básicas de quienes no son capaces de entrar en su órbita y, como consecuencia, quedan excluidos de la misma sociedad. Aunque no mencione expresamente la justicia social, en realidad subyace ese problema. Nuestra sociedad no puede ser indiferente a una situación que deja fuera a muchos que tienen derecho a la sociedad por ser humanos, y el libre mercado experimenta un límite en relación con ese problema.

15 The White House, Remarks by the President on economic mobility, December $4^{\text {th }}$, 2013 (http://www.whitehouse.gov/the-press-office/2013/12/04/remarks-presidenteconomic-mobility. Accedido en marzo 2014).

16 Francisco, Audiencia general, 5 de junio de 2013: "que algunas personas sin techo mueren de frío en la calle no es noticia. Al contrario, una bajada de diez puntos en las bolsas de algunas ciudades constituye una tragedia. Alguien que muere no es una noticia, ¡pero si bajan diez puntos las bolsas es una tragedia! Así las personas son descartadas, como si fueran residuos". 
La segunda afirmación ataca la posición que considera que, sin ninguna medida adicional, el crecimiento económico en un contexto de libre mercado es capaz por sí solo de incluir a los que están excluidos. Aunque más adelante volveremos sobre esta cuestión, aquí hemos de señalar que en la DSI anterior no se encuentra una referencia específica a esta teoría, y el mismo Papa señaló posteriormente, en la entrevista antes mencionada, lo siguiente:

"La única cita específica fue sobre las teorías de la «recaída favorable», que suponen que todo crecimiento económico, favorecido por la libertad de mercado, logra provocar por sí mismo mayor equidad e inclusión social en el mundo. Se prometía que, cuando el vaso hubiera estado lleno, se habría desbordado y los pobres se habrían beneficiado. En cambio sucede que, cuando está lleno, el vaso, por arte de magia, crece y así nunca sale nada para los pobres. Esta fue la única referencia a una teoría específica" ${ }^{17}$.

En cambio, como hemos visto en la DSI -concretamente lo recoge el Catecismo- sí se encuentra el rechazo de la regulación de la economía "únicamente por la ley del mercado" (CEC 2425) y la llamada a orientar el mercado al bien común con un marco jurídico y ético adecuados (cfr. también CA 42). Eso supone una intervención que no solo se refiere a la autoridad que tiene una especial responsabilidad respecto al bien común, sino también a los propios agentes del mercado y a la misma sociedad civil como corresponde al principio de subsidiaridad.

Como apuntábamos más arriba, la cuestión de la exclusión y la desigualdad tiene su correlato en el segundo grupo de números dedicados a la economía (EvG 202-208). Allí, y es también otro pasaje que ha levantado ampollas, Francisco señala que "ya no podemos confiar en las fuerzas ciegas y en la mano invisible del mercado. El crecimiento en equidad exige algo más que el crecimiento económico, aunque lo supone” (EvG 202). Cuanto hemos señalado sobre la necesidad de orientar el mercado al bien común por ser una dimensión más de la vida en sociedad explica lo que se afirma en este último número. Por eso, más allá de la cita específica de las teorías del derrame, nos parece que el fondo de la observación que hace el Papa tampoco es una novedad en la DSI.

En conjunto estos números responden a la intención analítica del Papa: son un análisis breve y no detallado de un problema serio de la

17 Francisco, “Jamás tener miedo ...", entrevista en La Stampa, 14-12-2013. 
sociedad actual a escala global. Lo que Francisco invitaba a llevar a cabo a la Iglesia - "estudiar los signos de los tiempos" (EvG 51) - es lo que él mismo hace aquí. En sus propias palabras, y excepción hecha de la referencia a las teorías del derrame, "no hablé desde un punto de vista técnico, traté de presentar una fotografía de lo que sucede"18. Como se ve es la necesidad de incluir en la sociedad a los pobres la que guía la denuncia del pontífice y es este punto también el que ha de orientar la reflexión y la respuesta a esta interpelación.

b) Problemas estructurales del sistema económico actual

La segunda gran cuestión planteada por el Papa se refiere a los problemas estructurales que acarrea el sistema económico y financiero actual. En este caso las ideas al respecto se encuentran distribuidas en las dos secciones dedicadas a la economía.

Uno de los problemas estructurales señalados por el Papa es precisamente el de la violencia, pero guarda relación con la exclusión, la desigualdad y lo que sucede en la práctica en el sistema económico actual. En palabras de Francisco, "[...] hasta que no se reviertan la exclusión y la inequidad dentro de una sociedad y entre los distintos pueblos será imposible erradicar la violencia" (EvG 59). La razón es clara: "cuando la sociedad abandona en la periferia una parte de sí misma, no habrá programas políticos [...] que puedan asegurar indefinidamente la tranquilidad" (EG 59).

La raíz de la violencia es la injusticia y en la mente del Papa esta tiene dos manifestaciones arraigadas en el momento presente: la primera, como se ha visto, es la exclusión y la inequidad que generan violencia; la segunda apunta grosso modo al sistema social y económico:

“[...] el sistema social y económico es injusto en su raíz. Así como el bien tiende a comunicarse, el mal consentido, que es la injusticia, tiende a expandir su potencia dañina y a socavar silenciosamente las bases de cualquier sistema político y social por más sólido que parezca. Si cada acción tiene consecuencias, un mal enquistado en las estructuras de una sociedad tiene siempre un potencial de disolución y de muerte. Es el mal cristalizado en estructuras sociales injustas, a partir del cual no puede esperarse un futuro mejor" (EG 59).

18 FrancisCo, “Jamás tener miedo ...”, entrevista en La Stampa, 14-12-2013. 
Aunque no menciona expresamente las "estructuras de pecado", el análisis del Papa apunta claramente en esa dirección. La cuestión es: ¿cuál es la injusticia o el mal que se encuentra en la raíz del sistema económico propiamente dicho? La respuesta se encuentra en dos frentes, siempre dentro de la perspectiva analítica antes mencionada:

a) "Los mecanismos de la economía actual promueven una exacerbación del consumo" (EvG 60) y esto por "la grave carencia de su orientación antropológica que reduce el ser humano a una sola de sus necesidades: el consumo" (55). Así se puede explicar que incluso "perdemos la calma si el mercado ofrece algo que todavía no hemos comprado" (54). Es decir, el consumismo es, a efectos prácticos, un problema estructural del sistema económico actual, que por una visión materialista de la vida cifra la felicidad en un consumo exacerbado que deshumaniza. Se entiende que este problema ha de ponerse en relación con la cuestión de la inequidad y la exclusión, pues el consumismo convive con los ejemplos gráficos de exclusión e inequidad descritos en el n. 53.

b) "Mientras las ganancias de unos pocos crecen exponencialmente, las de la mayoría se quedan cada vez más lejos del bienestar de esa minoría feliz. Este desequilibrio proviene de ideologías que defienden la autonomía absoluta de los mercados y la especulación financiera. De ahí que nieguen el derecho de control de los Estados, encargados de velar por el bien común" (EvG 56). Este pasaje, que como veremos ha levantado ampollas, tiene de nuevo su correlato en el segundo grupo de números dedicados a la economía. Se trata, por tanto, de otra idea de fondo que recorre el pensamiento del Papa: "mientras no se resuelvan radicalmente los problemas de los pobres, renunciando a la autonomía absoluta de los mercados y de la especulación financiera y atacando las causas estructurales de la inequidad, no se resolverán los problemas del mundo" (EvG 202).

En este caso el Papa entiende que la autonomía absoluta de los mercados y la especulación financiera es otra de las injusticias "radicales" que se encuentra en la base de los problemas del mundo. Nótese que el problema apunta a la ideología que niega todo derecho de intervención por parte del Estado. Como hemos visto la Iglesia es contraria a esa posición pero el Papa emplea la palabra "control", que tiene una connotación colectivista que no ha pasado desapercibida. Por lo demás, que el Estado 
tenga el encargo y deber de velar por el bien común es una afirmación absolutamente clásica de la DSI ${ }^{19}$. Esa es la función teórica de la autoridad, confiando en que lo sea en la práctica y lamentando también los casos en que de hecho no lo es.

\section{ALGUNAS REACCIONES AL DOCUMENTO EN ESTADOS UNIDOS}

La crisis económica ha puesto una vez más de manifiesto lo que desde hace tiempo numerosos académicos vienen señalando: el sistema económico que de hecho tenemos necesita una revisión profunda pues, entre otros motivos, las concepciones antropológicas y éticas que lo sustentan son claramente insuficientes ${ }^{20}$. Por eso las enseñanzas de Francisco son bienvenidas por muchos porque aportan luces y enriquecen la reflexión sobre un problema serio que importa a todos. También en Estados Unidos la aportación del Papa es bien recibida por muchas personas, incluida la primera autoridad del país. Sin embargo, de entre las numerosas reacciones aquí nos vamos a fijar solo en algunas que, bien por su autor o por el medio en que han aparecido, pueden tener una mayor influencia.

Hay algo que sorprende en no pocos de los comentarios sobre EvG en Estados Unidos: con bastante frecuencia los pronunciamientos magisteriales que se refieren a cuestiones de DSI tienden a ser vistos en clave política. Así, una afirmación es de corte republicano o demócrata, es liberal o izquierdista o es conservadora. Ya en el terreno de la economía, las afirmaciones tienden a ser vistas en clave capitalista o colectivista, $y$ entonces parece que irremediablemente uno ha de situarse a favor o en contra de la DSI. En ese contexto no sorprende que Rush Limbaugh, quizá uno de los locutores radiofónicos más conocidos del país, dijera que las afirmaciones del Papa son "puro marxismo" ${ }^{21}$. Es a este comentario al que parecía responder el Papa cuando afirmaba en la entrevista

19 Cfr. CDSI 168; CEC 1910; JuAn XXIII, Enc. Pacem in terris, 54 (AAS 55 [1963] 257-304); LeÓN XIII, Immortale Dei, 2 (AAS 18 [1885] 161-180); LeÓN XIII, Enc. Rerum novarum, 23 (AAS 23 [1890-1891] 641-670): "el Estado debe velar por el bien común como propia misión suya”.

20 Cfr., por señalar tan solo algún ejemplo, S. Zamagni, Por una economía del bien común (Ciudad Nueva, Madrid 2012); R. F. Crespo, Filosofía de la economía (Eunsa, Pamplona 2009).

21 "This is just pure Marxism coming out of the mouth of the pope" (R. Limbaugh, It's Sad How Wrong Pope Francis Is [Unless It's a Deliberate Mistranslation By Leftists], November 27 $7^{\text {th }}$ 2013. (http://www.rushlimbaugh.com/daily/2013/11/27/it_s_ 
mencionada: "no hablé como técnico, sino según la Doctrina social de la Iglesia. Y esto no significa ser marxista" 22 .

Por su parte, la revista First Things, un importante referente del pensamiento cristiano en Estados Unidos, publicaba un editorial a propósito de EvG. En ella, Russell Ronald Reno, actual editor de la revista, decía que "desafortunadamente, las abarcantes generalizaciones de Francisco sobre la economía son imprecisas e incluso irresponsables" ${ }^{23}$. El problema que señala Reno es que el Papa "ignora la manera en que las economías dominadas por el Estado espolean la corrupción y con frecuencia hacen más profunda la pobreza en vez de aliviarla, mientras que señala las teorías del derrame con una dura crítica”. Como se ve, Reno asume que el Papa propone el dominio de la economía por parte Estado, y eso es lo que le parece irresponsable. Sin embargo con esta afirmación va más allá de lo que el Papa dice en su texto y parece etiquetar las palabras de Francisco conforme a una estructura bipolar: si no es capitalismo, es economía estatal. En este contexto se entiende perfectamente que Juan Pablo II recordara en aquel conocido pasaje de Sollicitudo rei socialis que

"la doctrina social de la Iglesia no es, pues, una «tercera vía» entre el capitalismo liberal y el colectivismo marxista, y ni siquiera una posible alternativa a otras soluciones menos contrapuestas radicalmente, sino que tiene una categoría propia. [...] no pertenece al ámbito de la ideología, sino al de la teología y especialmente de la teología moral" ${ }^{24}$.

sad_how_wrong_pope_francis_is_unless_it_s_a_deliberate_mistranslation_by_ leftists. Accedido abril 2014).

22 Francisco, "Jamás tener miedo a la ternura", Entrevista en La Stampa,14-12-2013.

23 R. R. Reno, "Francis and the market" en First Things February 2014, 3-7; 3-4:

"Good questions [What's to be done about wage competition between workers in Bangalore, India, and Youngstown, Ohio? About the migration of people in search of economic opportunity? How will global finance be regulated? Pollution and climate change? And then there's the mother of all questions, the one Francis brings to the fore: How can we include as many people as possible in the prosperity being created by the capitalist revolution sweeping the globe?], but unfortunately Francis's sweeping generalizations about economics are inaccurate, and even irresponsible. He ignores the ways in which state-dominated economics encourage corruption and often deepen rather than alleviate poverty while singling out trickle-down theories for harsh criticism".

24 Juan Pablo II, Enc. Sollicitudo rei socialis, 41 (AAS 80 [1988] 513-586). A este propósito cfr. A. Belloce, "Qué es y qué no es la Doctrina Social de la Iglesia”, en Scripta Theologica 44/2 (2012) 337-366. 
Robert Sirico, cofundador y presidente del Acton Institute -un think-tank de inspiración católica que defiende el libre mercado en un contexto informado por los valores morales- realizó unas declaraciones en un vídeo tres días después de la publicación de EvG. Además de alabar el documento, hacía notar con tono elegante -y es algo que muchos comentarios han repetido de un modo u otro- que es un hecho incontestable que la economía basada en el mercado global ha reducido la pobreza como no lo ha conseguido nunca ningún otro modelo de organización económica. Por otra parte Sirico lanza una serie de preguntas: ¿¿ónde es el mercado absolutamente autónomo? ¿Quién está defendiendo un mercado desconectado de la moralidad, de la ley, de la cultura? Existe una conciencia general de la necesidad de leyes o reglas adecuadas para que los mercados puedan funcionar. Sirico se pregunta también si hay diferencia entre lo que dice Juan Pablo II sobre el mercado en "Centesimus annus" y la experiencia que puede tener Francisco de un capitalismo de compadreo (crony capitalism) o un capitalismo de Estado (State capitalism), como el que Francisco puede haber visto en Argentina o el que se da en otros lugares de Latinoamérica ${ }^{25}$.

En un artículo titulado "Coincidiendo con el papa Francisco"26, Michael Novak señala que una exhortación no es un documento que destaque por un cuidadoso argumento, pues eso es más bien el trabajo de una encíclica. Según Novak una exhortación apostólica es una ocasión algo informal para que el Papa exponga su visión de pastor; es como un sermón u homilía ${ }^{27}$. Novak se muestra de acuerdo con el Papa porque le parece que el capitalismo que el Papa tiene en mente es el que proviene de su experiencia en Argentina. No obstante considera que la Exhortación

25 R. SiRICO, Comments on the economics view of Pope Francis in Evangelii gaudium (cfr. http://blog.acton.org/archives/63186-video-rev-robert-sirico-responds-popefrancis-economic-views-evangelii-gaudium.html. Accedido abril 2014).

26 M. NovaK, "Agreeing with Pope Francis", en National Review Online December $7^{\text {th }}, 2013$ (http://www.nationalreview.com/article/365720/agreeing-pope-francismichael-novak. Accedido en marzo de 2014).

27 "An exhortation is not so much a teaching document laying out a careful argument - that is the task for an encyclical. Rather, it is more like a sermon, a somewhat informal occasion for the pope to set out his vision as a pastor, and to present it as an invitation to deeply felt piety and devotion" (M. NovaK, "Agreeing with Pope Francis"...). Sin embargo eso no es exacto. Bastaría poner los ejemplos de "Christifideles laici" o "Evangelium nuntiandi", que no son sermones y tienen una cuidada argumentación. 
contiene una serie de afirmaciones altamente partidistas y tendenciosas, que "parece que están fuera de la normal tranquilidad y generosidad de espíritu de este Papa". En concreto se refiere a expresiones como "trickledown theories", la alusión a la "mano invisible", la expresión "idolatría del dinero" o aquella otra de "confianza en el Estado «encargado de velar por el bien común»"28.

De la expresión "idolatría del dinero" solo se puede decir que, además de estar recogida hace años en el Catecismo (cfr. CEC 2425), está tranquila y establemente asentada en el pensamiento del Papa, pues en seis meses la usó tres veces y la de EvG fue la tercera ${ }^{29}$. Respecto a la función del Estado de velar por el bien común, además de que el Papa no dice que haya que confiar en el Estado, ya se apuntó más arriba que es doctrina fuertemente arraigada en el magisterio social desde León XIII.

Distinto es el caso de la primera de las expresiones. Novak sostiene $-\mathrm{y}$ en esto como veremos le sigue Chafuen- que traducir "teorías del derrame" por trickle-down theories no hace justicia al texto. Según Novak hubiera sido mejor emplear el término spill-over porque trickle-down theory es la manera peyorativa e irónica que usan y usaban quienes se oponían al capitalismo y a las reformas de la era Reagan para desautori-

28 "About six of his swipes are so highly partisan and biased that they seem outside this pope's normal tranquillity and generosity of spirit [...] Among these are "trickledown theories", "invisible hand", "idolatry of money", "inequality", and "trust in the state "charged with vigilance for the common good»" (M. NovaK, "Agreeing with Pope Francis"...).

29 Las dos anteriores fueron, además, intervenciones orales: FrANCISCO, Encuentro con el mundo laboral, Cagliari, 22 de septiembre de 2013: "[la falta de trabajo es] Un sufrimiento [...] que te lleva -perdonadme si soy un poco fuerte, pero digo la verdad- a sentirte sin dignidad. Donde no hay trabajo, falta la dignidad. Y esto no es un problema solo de Cerdeña [...] es la consecuencia de una elección mundial, de un sistema económico que lleva a esta tragedia; un sistema económico que tiene en el centro un ídolo, que se llama dinero. Dios ha querido que en el centro del mundo no haya un ídolo, sino que esté el hombre, el hombre y la mujer, que saquen adelante, con su propio trabajo, el mundo. Pero ahora, en este sistema sin ética, en el centro hay un ídolo y el mundo se ha vuelto idólatra de este "dios-dinero». Manda el dinero". Cfr. también Francisco, Discurso a un grupo de nuevos embajadores, 16 de mayo de 2013 (Disponible en: http://www.vatican.va/holy_father/francesco/speeches/2013/may/documents/ papa-francesco_20130516_nuovi-ambasciatori_sp.html). 
zarlas (según Novak, los demócratas contra los republicanos ${ }^{30}$ ). De ese modo la traducción inglesa transmite un tono "politizado" que no tiene el supuesto original español. Seguramente se trata de una apreciación justa y muestra una vez más la importancia del trabajo de traducción de los documentos magisteriales ${ }^{31}$.

En todo caso la idea que quiere transmitir Novak, y que es ya clásica en sus trabajos, es que el capitalismo ha hecho lo que no ha conseguido ningún otro sistema: mayores tasas de empleo, mayores salarios, gran cantidad de nuevas empresas e iniciativas personales, posibilidades de movilidad social ascendente sin paralelo, oportunidades de salir de la pobreza en menos de diez años para muchos inmigrantes, etc ${ }^{32}$. Por eso, según Novak, el comentario de que esas teorías no se han demostrado nunca se comprende en un lugar como Argentina, donde las posibilidades de movilidad social ascendente son mucho más reducidas, pero en otros países las cosas no son como dice el Papa. Novak defiende que "América ha sido más «inclusiva» del pobre que ninguna otra nación en la tierra”. Aquí sin embargo la cuestión sería más bien si esa inclusión o esas posibilidades de movilidad social se han dado únicamente por el "derrame" del crecimiento económico desde los estratos superiores o también en conjunción con otro tipo de medidas, sea por parte de la sociedad civil, o de una intervención legislativa favorable o de políticas económicas o sociales ${ }^{33}$.

Más allá de si esa teoría se verifica o no -tarea que corresponde dilucidar a los economistas- el hecho es que, como se ve en el comentario de Novak, estas frases de EvG han llevado a no pocos en Estados Unidos a

30 El mismo Obama habla de trickle-down ideology en el discurso en que cita al Papa (cfr. The White House, Remarks by the President on economic mobility, December $\left.4^{\text {th }}, 2013\right)$.

31 Realmente recoger las polémicas ocasionadas por las traducciones de los documentos del Magisterio a lo largo de la historia daría lugar a un largo estudio.

32 Cfr. M. NovaK, "Agreeing with Pope Francis"; M. NovaK, El espíritu del capitalismo democrático (Tres Tiempos, Buenos Aires 1984).

33 En la visión de Novak las cosas han sucedido así: "The upward movement promoted by certain capitalist systems is the experience -not a "crude and naïve trust"- of a large majority of Americans. Trickle-down is not an apt description of what has happened here; rather, what has been experienced is wealth "welling up from below." Exactly this is what continues to attract millions of immigrants into our economy" (M. NovaK, "Agreeing with Pope Francis"). El sueño americano, en una palabra. La posibilidad que existe allí de progresar desde abajo. 
pensar que se trata de una crítica al sistema capitalista en cuanto tal y no tanto a sus excesos. Por eso Novak insiste en los logros innegables que ha producido ese modo de organizar la economía. En contraste, Novak resalta que donde ha prevalecido una torpe intervención estatal -para él es el caso de Argentina- las posibilidades de movilidad social ascendente se han esfumado y la pobreza se ha enraizado fuertemente ${ }^{34}$. Con todo, Novak se queda sobre todo con la intención del documento, que se propone romper la última vuelta de las cadenas de la pobreza: todavía quedan mil millones de personas encadenadas y los judíos, cristianos y humanistas -dice Novak- han de llevar a cabo esta tarea.

Por último, Novak supone que puesto que EvG es un documento más bien informal, en el futuro el Papa desplegará totalmente sus argumentos sobre la política económica que mejor puede ayudar a los pobres a salir de su situación. Para eso, concluye, "solo puedo imaginar que el Papa ya habrá comenzado a consultar sobre esta materia”. Sin embargo, difícilmente puede esperarse de un Pontífice políticas económicas para ayudar a los pobres a salir de su situación. Las orientaciones de la DSI no deben descender a detalles técnicos, pues esa es tarea que corresponde a los profesionales de esos campos, a los fieles laicos.

Alex Chafuen, presidente de Atlas Economic Research Foundation, critica en Forbes" la traducción de "teorías del derrame" por "trickledown theories", expresión que se utiliza normalmente para denigrar el libre mercado. También le parece que spill-over es mejor pero señala que en realidad la palabra "derrame" quiere reflejar lo que Adam Smith dijo en su libro La riqueza de las naciones: la gran multiplicación de la pro-

34 "As the 20th century began, Argentina was ranked among the top 15 industrial nations, and more and more of its wealth was springing from modern inventions rather than farmland. Then a destructive form of political economy, just then spreading like a disease from Europe -a populist fascism with tight government control over the economy-dramatically slowed Argentina's economic and political progress. Instability in the rule of law undermined economic creativity. Inflation blew to impossible heights. (I brought home from Argentina in the early 1980s a note for a million Argentine pesos that had declined in worth to two American pennies). Over three generations, very little of the nation's natural wealth and opportunity for social advancement has overflowed into the upraised buckets of the poor" (M. NovaK, "Agreeing with Pope Francis").

35 A. Chafuen, "Pope Francis and the economists", en Forbes.com December 4th, 2013 (http://www.forbes.com/sites/alejandrochafuen/2013/12/04/pope-francisand-the-economists-2/. Accedido abril 2014). 
ducción como consecuencia de la división del trabajo "da lugar a esa opulencia universal que se extiende [derrama] a los estratos más bajos de la población" en una "sociedad bien gobernada" 36 . Chafuen apunta que Smith jamás defendió la autonomía absoluta del mercado porque ponía como condición de ese "derrame" el que la sociedad estuviera "bien gobernada".

Como se ve el presidente de ATLA quiere introducir una precisión en una expresión y en una teoría que, como la de la mano invisible, ha sido interpretada con un sentido particular a lo largo de la historia. Chafuen quiere aclarar lo que en realidad dijo Smith pero, más allá de eso, está poniendo de manifiesto un problema subyacente: nos encontramos con expresiones que, ya antes de que las utilice el papa Francisco, son objeto de interpretaciones distintas. Como consecuencia, el Papa, al usarlas, incorpora a su texto ese debate.

Por último, según Chafuen la visión que expresa el Papa en EvG cuando se refiere a trickle-down theories está bajo la influencia del pensamiento de algunos de los economistas que colaboran con el Vaticano, en concreto en la Pontificia Academia de Ciencias Sociales, y cita expresamente a Joseph Stiglitz. Chafuen invita a otros economistas partidarios del libre mercado a ganarse un puesto en esos ambientes para influir con sus verdades y termina con una frase de un profesor suyo: "si los economistas no saben economía, ¿cómo puedes recriminar a los obispos por su economía?" 37 . Aunque la suposición de Chafuen se apoya en la arena movediza de la especulación, en el fondo pone de manifiesto que nos encontramos ante visiones económicas que son objeto de discusión y por eso generan controversia. El Papa, por su parte, reconoce en la entrevista que esa mención fue la única cita de carácter técnico en la exhortación, por lo que se puede comprender también que en el ámbito de la economía haya quien reaccione a ese pasaje concreto. Por lo demás, el mismo Chafuen sostiene en este artículo que es fácil encontrar países donde coexisten un notable crecimiento económico, la injusticia y la exclusión. China o India serían un ejemplo. Sin embargo, para Chafuen la libertad de mercado es el mejor antídoto contra la corrupción,

36 A. Chafuen, "Pope Francis and the economists" (derramar proviene de spread, extender).

37 "If economists do not know economics, how can you blame the bishops for their economics?" (A. Chafuen, "Pope Francis and the economists"). 
y donde hay menos libertad hay mucha más corrupción. De nuevo nos encontramos con el debate entre más libertad o mayor intervención del Estado en economía.

En un artículo publicado en el National Catholic Reporter ${ }^{38}$, Andrew Abela, decano de la facultad de económicas y empresariales de la Catholic University of America, señala que la esencia del mensaje del Papa es que la alegría que supone el encuentro con Jesucristo ha de traducirse en la expansión de la evangelización, con un esfuerzo renovado de servir a los pobres. El Papa pide pequeños gestos diarios de solidaridad pero también esfuerzos para eliminar las causas estructurales de la pobreza y promover el desarrollo de los pobres (EvG 188).

¿Cuáles son esas causas estructurales? Para Abela se trata de la absoluta autonomía de los mercados (202). El Papa no está condenando el capitalismo y proponiendo el socialismo en su lugar porque eso supondría separarse de la DSI. Tampoco está condenando la mítica economía de laissez faire porque el Papa sabe que como tal no existe en ningún lugar; ni tampoco condena los mercados como tales, porque sabe igualmente que han sido alabados por la DSI. Según Abela, lo que Francisco critica es la ideología según la cual cuando los hombres son dejados a sí mismos a la hora de establecer contratos libres con los demás el resultado será el mejor mundo de entre los posibles. La idea es buena -el libre mercado produce los mejores resultados-, el problema es que esa idea se extienda a todo lo demás. Sin reglas claras para la actividad económica, sin comportamiento honesto de parte de quienes interactúan en el mercado, no habrá eficiencia ni justicia. Por tanto, se hace necesaria la orientación del mercado hacia el bien común.

Para Abela los problemas se están produciendo en las situaciones a que alude el Papa. En primer lugar, cuando se da un capitalismo de compadreo o amiguismo - crony capitalism-, donde las empresas dependen más de sus contactos políticos que de su actuación en los mercados. Allí la autonomía absoluta reina en cuanto lleva a hacer presión mediante lobbies para cambiar el marco jurídico y obtener así favores especiales (nuevas normas que inhiben la competencia, etc). El segundo ejemplo

38 A. ABELA, “The economic message of Pope Francis' «Evangelii Gaudium»", en National Catholic Reporter December 9 ${ }^{\text {th }}, 2013$ (http://www.ncregister.com/dailynews/the-economic-message-of-pope-francis-evangelii-gaudium/. Accedido en abril 2014). 
que pone Abela es el fenómeno llamado "el mercado me hizo actuar asî". Es decir, la competencia en el mercado me fuerza a actuar de esta o aquella manera. Algunas veces es así pero, según Abela, otras veces responde a la falta de imaginación por parte de los directivos de las empresas, que no se plantean distintas alternativas porque dan por supuesto que hay que funcionar así. Por contraste, hay empresas que se han tomado el trabajo de mejorar las capacidades de los trabajadores para que sean más productivos y puedan recibir mayores salarios. Un tercer ejemplo de causa estructural de la pobreza es la idolatría del dinero. Dejamos que el consumismo guíe nuestro comportamiento y se pierde de vista el destino universal de los bienes.

La conclusión que saca Abela es doble: EvG llama a ser creativos para buscar la manera de incluir a los pobres en la actividad económica y exhorta a que rechacemos el consumismo y el desgaste y debilidad que engendra. Entonces -explica Abela- serviremos al Señor con alegría y crearemos más prosperidad económica para todos porque la inequidad y pérdida de productividad de tanta gente pobre es, además de todo, un lastre para el crecimiento de la economía global. Si Novak acababa imaginando que el Papa estará trabajando ya en un documento para precisar más la política económica que ayudará a erradicar la pobreza, Abela termina imaginando más bien lo que mil doscientos millones de católicos pueden hacer si trabajan diaria y diligentemente para mejorar la vida de los pobres.

Finalmente, James Pethokoukis, del "American Enterprise Institute" -un conocido think-tank asentado en Washington que defiende la libertad, mayores oportunidades para el individuo y el fortalecimiento de la libertad de empresa- escribe un breve comentario en el National Review Online ${ }^{39}$. Básicamente, Pethokoukis considera que aunque los logros del capitalismo son innegables tampoco cabe un triunfalismo porque queda mucho por hacer. Por eso, los partidarios del libre mercado no deberían sorprenderse porque Francisco llame al esfuerzo para erradicar la exclusión y la inequidad o afirme que el mero crecimiento económico no es

39 J. Pетнокоuкis, "What should a Pope say about capitalism?", en National Review Online December 2nd, 2013 (http://www.nationalreview.com/article/365192/whatshould-pope-say-about-capitalism-james-pethokoukis. Accedido en abril 2014). 
suficiente ${ }^{40}$. Más allá de esto, el comentario refiere los pasajes que han gustado a quienes son de izquierdas y los que en cambio han parecido bien a los conservadores. Aunque Pethokoukis señala que el centro del mensaje de EvG es Cristo mismo, el comentario en su conjunto refleja la tendencia extendida en estos ámbitos a leer los documentos en clave política.

\section{OBSERVACIONES CONCLUSIVAS}

Por último, una vez analizados algunos comentarios significativos en Estados Unidos, ofrecemos algunas observaciones finales sobre la Exhortación agrupadas en cinco puntos.

1. En el conjunto, las observaciones del Papa sobre la economía reflejan la constante preocupación de la DSI por los bienes y exigencias implicados en la justicia social y por la necesidad de que la economía, como la política, estén realmente orientadas al servicio a la persona humana y de manera particular hacia aquellos que han quedado excluidos de la sociedad. En este sentido la sustancia del mensaje de Francisco no supone novedad alguna en el contexto de la DSI, como por otra parte señaló el propio Papa en la entrevista posterior a la publicación del documento.

2. En las reacciones a EvG en Estados Unidos analizadas concurren distintos factores: por un lado, salvo alguna excepción, están moduladas por la asentada tendencia a leer en clave republicana o demócrata, izquierdista o conservadora, capitalista o comunista, las intervenciones del Magisterio. Por otro lado, utilizando la expresión trickle-down theory, la traducción inglesa ha promocionado, reforzado y contribuido a la lectura política del documento y, en consecuencia, a la mayor viveza de la controversia. En tercer lugar, aun contando con que el Papa quisiera expresar una idea precisa, los términos o ideas que emplea ("teorías del derrame", "mano invisible") están de suyo sujetos a discusión o a diferente interpretación por parte de los profesionales del campo de la economía, de forma que el uso de esas expresiones

40 Cfr. J. Pетнокоukis, "What should a Pope say about capitalism?": "Pro-market advocates need to consider that faster GDP growth may be necessary but not sufficient, that a rising tide may not lift all boats if accelerating automation means a vast swath of workers face unemployment or stagnant wages, as some economists on the left and right warn". 
genera controversia independientemente de la intención del Papa. En cuarto lugar, el registro que emplea el Papa y su intención expresa de no ofrecer un análisis completo sobre estas cuestiones ha hecho también que los comentarios se afanen en la interpretación sobre qué ha dicho o a qué se refiere en concreto el Romano Pontífice en uno u otro lugar, o sobre las precisiones o correcciones que deberían hacerse para hacer justicia a la realidad completa. En este sentido, se observa una dificultad en el ámbito académico para integrar el tipo de registro de la Exhortación en el tratamiento y reflexión sobre las cuestiones económicas.

3. Dicho lo anterior, cabe el riesgo de quedarse en la discusión acerca de lo que ha querido decir el Papa y si sus argumentos sobre los asuntos económicos son acertados o no. Sin embargo atascarse en esa discusión sería un error porque supone perder de vista lo que sin duda es un punto esencial pretendido por el Papa cuando se adentra en cuestiones económicas: EvG es una llamada positiva a la acción impulsada por el Evangelio para lograr la inclusión social de los pobres. Se trata de hacer más porque muchas personas se están quedando atrás. Más allá de la denuncia de la situación a corregir, el documento invita a la acción por superación que sirva a la justicia social. Preocupa al Papa que se pongan los medios efectivos para cambiar la situación y por eso los pasajes exhortativos buscan mover a la acción inteligente a quienes tienen capacidad de decisión. Francisco señala el fin a conseguir, que es integrar de nuevo a quienes quedan excluidos, o con otras palabras, la creación de oportunidades: "decisiones, programas, mecanismos y procesos específicamente orientados a una mejor distribución del ingreso, a una creación de fuentes de trabajo, a una promoción integral de los pobres que supere el mero asistencialismo" (EvG 202).

Por emplear una imagen, el Papa señala que hay que cruzar al otro lado del río. Se puede discutir si el mejor modo de hacerlo es construyendo un puente, haciendo un túnel, por barco, por aire o a nado; pero si la discusión termina en que de hecho no pasamos al otro lado porque no nos ponemos de acuerdo en cómo hacerlo, hemos errado el punto y, por supuesto, "mientras tanto, los excluidos siguen esperando".

4. En esta misma línea vale la pena prestar atención a una idea que, aunque aparece en otro lugar del documento, influye en los pasajes sobre 
la economía y constituye a mi entender una valiosa orientación para la acción. Se trata de la importancia de "iniciar procesos" (EvG 223):

“[...] trabajar a largo plazo, sin obsesionarse por resultados inmediatos. [...] Se trata de privilegiar las acciones que generan dinamismos nuevos en la sociedad e involucran a otras personas y grupos que las desarrollarán, hasta que fructifiquen en importantes acontecimientos históricos. Nada de ansiedad, pero sí convicciones claras y tenacidad (EvG 223). A veces me pregunto quienes son los que en el mundo actual se preocupan realmente por generar procesos que construyan pueblo, más que por obtener resultados inmediatos que producen un rédito político fácil, rápido y efímero, pero que no construyen la plenitud humana" (EvG 224).

Desde ahí puede entenderse que en la parte dedicada a la economía el Romano Pontífice invite a crear con valentía "procesos" (EvG 202) que conduzcan al fin deseado. Por otra parte, es interesente llamar la atención sobre el tipo de procesos que tiene en mente el Papa: han de ser procesos bien pensados, y en concreto que superen "el mero asistencialismo". Con otras palabras, los procesos han de ser conformes al principio de subsidiaridad, porque no se trata de que los excluidos esperen pasivamente en la orilla a que alguien les lleve al otro lado, sino de que también puedan ser incluidos en el mismo esfuerzo por lograr la solución ${ }^{41}$.

Por otra parte, se quiera o no, el hecho de la globalización hace difícil crear un proceso que no necesite o implique a otros países y por eso el tipo de acción que el Papa tiene en mente apunta en una dirección concreta:

"[...] cada vez se vuelve más difícil encontrar soluciones locales para las enormes contradicciones globales, por lo cual la política local se satura de problemas a resolver. Si realmente queremos alcanzar una sana economía mundial, hace falta en estos momentos de la historia un modo más eficiente de interacción que, dejando a salvo la soberanía de las naciones, asegure el bienestar económico de todos los países y no solo de unos pocos" (EvG 206).

En realidad, estos procesos requieren de un modo u otro una conversión porque el Papa señala problemas de calado como el consumis-

41 En este sentido Francisco es neto: "estoy lejos de proponer un populismo irresponsable" (EvG 204). 
mo, las desigualdades escandalosas, la exclusión, etc., que de hecho se dan en la realidad económica actual y requieren cambios personales y colectivos.

5. Por último, nos ha llamado la atención que ningún comentario se ha ocupado expresamente del sistema financiero como tal. El Papa hace dos referencias expresas a la especulación financiera como uno de los males estructurales de la práctica del sistema económico actual pero sorprendentemente nadie ha dicho nada a ese respecto. En vista del perfil financiero de las crisis económicas de las últimas décadas, es urgente analizar qué sucede allí ${ }^{42}$. En ese análisis, además de estudiar el funcionamiento de los mercados y agentes económicos es igualmente o incluso más importante prestar atención a la conducta, decisiones y presupuestos de funcionamiento de los gobiernos. Si se trata de iniciar procesos, nos parece que el primer ámbito por el que habría que comenzar es el ámbito financiero.

Comprobar que una intervención del Romano Pontífice sirve para hacer pensar, para espolear las conciencias y poner sobre la mesa cuestiones muy importantes para la sociedad es sin duda una realidad positiva. Por encima de las discusiones sobre los pasajes de EvG que se ocupan de la economía, vale la pena considerar que es ante todo una invitación a colaborar con nuestra acción inteligente y conforme a nuestras posibilidades en el proyecto divino para el mundo. Esa tarea es sin duda una consecuencia importante del anuncio del Evangelio, es ocasión de encuentro con Jesucristo y por eso fuente de auténtica alegría.

42 Cfr. G. Guitián, “¿Son las finanzas una «estructura de pecado»?”, en Scripta Theologica 45/2 (2013) 301-334. 